\title{
Linkage Between GDP And Emissions: A Global Perspective On Environmental Kuznets Curve
}

Kanwalroop Kathy Dhanda, (Email: dhanda@up.edu), DePaul University Bahram Adrangi, (Email: adrangi@up.edu), University of Portland Arjun Chatrath, (Email: chatrath@up.edu), University of Portland

\begin{abstract}
In this paper we present a mathematical framework for the linkage between GDP and emissions for a particular nation or group of nations. The properties of the functions will be discussed, followed by an empirical section that illustrates the methodology employed. We will also present the greenhouse gases emissions data and GDP data and discuss the results of the empirical study.
\end{abstract}

\section{INTRODUCTION}

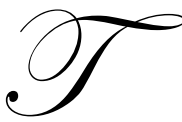

he Kyoto Protocol, a follow-up to the 1992 United Nations Framework Convention on Climate Change (UNFCCC) called for drastic cuts in the emissions of greenhouse gases as it set binding quantified emission limitation and reduction commitments (QELRCs) for the period 2008-12 (UN Climate Change Convention 1997). Annex B of the Protocol (see the Appendix) lists the targets for each of the industrialized countries. The Protocol allows the countries a high amount of flexibility in attaining these targets, mainly due to the economic impacts of the reduction of greenhouse gases. It is also hoped that this flexibility will reduce the overall costs of meeting the targets via an optimization of resources in every country by market forces (Vrojlik and Grubb, 2000).

The Protocol provides five dimensions of flexibility. Two of these are internal, the basket of $\mathrm{CO} 2$ and other greenhouse gases and land-use change and forestry, also referred to as the sinks. The other three are external dimensions that are concerned with international transfers of emissions and would help countries with QELRCs to achieve their targets. The three instruments are Joint Implementation (JI), Emissions Trading (ET) and Clean Development Mechanism (CDM).

Article 6 of the Kyoto Protocol allows an Annex B party to meet its commitment by acquiring or transferring emission reduction units from projects implemented in other Annex B countries and this article is referred to as JI. Article 17 of the Protocol allows Annex B countries to trade their assigned amounts of emissions and is referred to as ET. Article 12 of the Protocol involves participation by both Annex B and non-Annex B parties and aims to achieve sustainable development and compliance with QELRCs and is referred to as CDM (Gupta, 2000).

The six greenhouse gases that are under consideration are carbon dioxide (CO2), nitrous oxide (NOx), methane (CH4), and industrial gases such as hydrofluorocarbons (HFCs), perfluorocarbons (PFCs) and sulfur hexafluoride (SF6). Refer to the appendix for a list of the greenhouse gases and the processes that are considered in the accounting of the greenhouse gases. The protocol allows some flexibility to nations in terms of how they achieve the emissions reductions. The protocol also calls for an international trading regime that will be established whereby industrial countries can trade excess emission permits with each other (UN Climate Change Convention 1997).

The push behind the Kyoto Protocol is mainly due to concerns of climate change. Most of the scientists are in agreement that we are witnessing climate change that is due to the warming effect of the greenhouse gases. 
Thirteen of the fifteen European Union member states have ratified the Kyoto agreement. It was hoped that EU could collectively ratify the protocol by the Johnannesburg summit but there were delays on the parts of Greece and Italy to ratify Kyoto (Kyoto ratification timetable in doubt, 2002). The Bush administration in the United States has refused to ratify the protocol, focusing instead on formulating other alternatives. Representatives of Canada, United States, and Mexico also met in Toronto to discuss steps towards establishing a trading regime to reduce greenhouse gases in North America (U.S., Canada and Mexico may set up emissions trading, 2003). In Japan, the lower house of parliament has approved a government proposal to join up whereas Russia is still going back and forth on its decision to join though Putin has told key ministries to sign up the protocol (Putin tells Ministries to Salvage Kyoto, 2004). The current statistics from the United Nations Framework Convention on Climate Change (UNFCCC) can be found at its website (Kyoto Protocol Status of Ratification 2004).

The Environment Kuznets Curve (EKC) attempts to postulate whether there a U-shaped curve exists between emissions and economic development. A primer on this curve provides detailed information on the general form of the EKC curve and its theoretical implications (Yandle, Vijayaraghavan, Bhattarai, 2002).

This paper focuses on the linkage between emissions and the level of GDP in a nation. We aim to determine whether there exists any kind of relationship between these two variables. Specifically, we examine whether this relationship consistent with the EKC. We hope that an analysis of this relationship might provide insights into the policy making that, in the long run, will put us in a trajectory of reducing greenhouse gas emissions.

The paper is organized as follows. In Section II, we develop the theoretical basis of the paper. Specifically, we will develop an optimization problem faced by of a specific nation in which the utility is maximized while ensuring that the cost of production and emissions is constrained. In Section III, we shall propose the methodology used in the paper. Section IV will focus on the empirical portion of the paper and the discussion of the results derived in the empirical study. The data will also be discussed in Section IV. Lastly, we shall summarize our results and present conclusions in Section V.

\section{THE MODEL WITH THE OPTIMIZATION PROBLEM}

In this section, we develop the theoretical model that will explore the linkage between emissions, the GDP of a nation and the costs involved in reducing emissions.

Let $\mathrm{U}$ denote the utility function for a specific nation. If $\alpha, \beta$ denote the weights typically used in a CobbDouglas function, then the utility function can be written as:

$\mathrm{U}=\mathrm{GDP}^{\alpha} \mathrm{EM}^{-\beta}$

where EM denotes the overall emissions in the nation and GDP denotes the gross domestic product for a nation. The constraint faced by the nation takes the following form:

$\mathrm{S}=\psi \mathrm{GDP}-\mu \mathrm{EM}$

$\mathrm{S}$ represents a certain dollar amount of national wealth that is the GDP minus the dollar value of the adverse effect of emissions. This is consistent with economic literature where GDP is considered an overestimation of actual measure of national welfare because it ignores the negative externalities resulting from the production process. For example, the cleanup of an oil spill will increase the actual value of the GDP while, in reality, environmental disasters should not be adding to the national measure of GDP.

Most nations have been opposed to international environmental agreements in fear of having to lower their standard of living. This indicates that most nations have standard of living constraint similar to equation (2). Furthermore, nations realize that their utility is a function of not only the level of GDP, rather, it is a function of the level of GDP and resulting pollution. For example, additional pollution is admissible by most nations if it produces incremental levels of GDP. The graph in Figure 1 depicts the optimization problem at hand. The graph in Figure 1 
states that the optimal level of GDP and emissions will be at the intersection of the CIC curve and the S constraint where CIC denotes the consumer indifference curve.

This constraint states that the costs for controlling the emissions will take on the form of a weighted sum of a proportion of GDP minus a proportion of emissions. Essentially, the value of GDP plus value of emission can be constrained by this cost function.

Hence, algebraically, the optimization problem faced by a particular nation is:

Maximize $\mathrm{U}=\mathrm{GDP}^{\alpha} \mathrm{EM}^{-\beta}$

Subject to $S=\psi \mathrm{GDP}-\mu \mathrm{EM}$

and non-negativity conditions:

GDP $>=0, \mathrm{EM}>=0, \psi=1, \mu>0, \alpha>0, \beta>0$.

The Lagrangean for this optimization problem can be expressed as:

$\mathrm{L}=\mathrm{GDP}^{\alpha} \mathrm{EM}^{-\beta}+\lambda[\mathrm{S}-\psi \mathrm{GDP}+\mu \mathrm{EM}]$

\section{First-order Conditions}

The first-order conditions can be derived by taking the first partial of the Lagrangean with respect to the arguments, in this case, GDP, EM and $\lambda$. These first-order conditions will be used to derive the functional linkages between the arguments in the optimization problem.

$\mathrm{L}_{\mathrm{GDP}}=\alpha \mathrm{GDP}^{\alpha-1} \mathrm{EM}^{-\beta}-\lambda \psi=0$

Rearranging this term yields:

$\alpha \mathrm{GDP}^{\alpha-1} \mathrm{EM}^{-\beta}=\lambda \psi$

$\mathrm{L}_{\mathrm{EM}}=-\beta \mathrm{GDP}^{\alpha} \mathrm{EM}^{-\beta-1}+\lambda \mu=0$

Rearranging this term yields:

$\beta \mathrm{GDP}^{\alpha} \mathrm{EM}^{-\beta-1}=\lambda \mu$

$\mathrm{L}_{\lambda}=\mathrm{S}-\psi \mathrm{GDP}+\mu \mathrm{EM}=0$

Rearranging this term yields:

$\mathrm{S}=\psi \mathrm{GDP}-\mu \mathrm{EM}$

Second-order Conditions

The second-order conditions will be derived and arranged in a bordered Hessian matrix. The sufficient conditions for a maximization problem require that the determinant of the bordered Hessian alternates in sign. Given that we have a three by three matrix, the determinant of the Hessian needs to be positive definite. The derivation of the second-order conditions and the determinant is discussed in the Appendix. 
Looking back to the first-order conditions, we want to determine the relationship between emissions and the GDP. To accomplish this, we re-arrange the first-order conditions.

Dividing equation (8) by equation (10) and re-arranging the terms yields:

$\psi / \mu=\alpha \mathrm{EM} / \beta \mathrm{GDP}$

Upon further rearrangement of the terms, we get the final forms for both the GDP and the emission function. This way, we can solve for the choice arguments for the two variables, GDP and EM.

$\mathrm{GDP}^{*}=\mu \alpha \mathrm{EM} / \psi \beta$

$\mathrm{EM}^{*}=\psi \beta \mathrm{GDP} / \mu \alpha$

Equations (14) and (15) illustrate the linkage between GDP and emissions. This direct relationship between a nation's GDP and emissions will be explored in the empirical section.

Furthermore, we can substitute equations (14) and (15) in the cost constraint (2) to get:

$\mathrm{C}^{*}=\mu \mathrm{EM}^{*}[\alpha / \beta+1]$

$\mathrm{C}^{*}=\psi \mathrm{GDP}^{*}[1+\beta / \alpha]$

Equations (16) and (17) provide the cost term as separate functions of emissions and GDP, respectively.

\section{METHODOLOGY}

In this section, we would like to ascertain the relationship between the GDP of a nation and its level of emissions. As a part of the push for the Kyoto protocol, the data collection really begins from the year 1990. Also, we are focusing our research on the Annex B nations that are comprised of the industrial western nations, emerging economies in Eastern Europe, Russia, Japan, Australia, and New Zealand. The official site of the UNFCCC collects data for emissions on a worldwide basis but the data are either incomplete or missing for most of the nations in nonAnnex B group.

Initially, we offer some empirical tests of the relationship between emissions and measures of GDP for two hundred and twelve nations. The data are retrieved from United Nations (UNSTATS) database. A partial motivation for the empirical investigation is to establish whether Environmental Kuznets Curve is verifiable for this sample of industrial nations. This curve attempts to determine whether an inverted U-shaped curve exists between emissions and economic development. Some studies indicate that the EKC is the strongest for particulate matter, sulfur oxides, nitrogen oxides, and carbon monoxide (Selden, Forrest, and Lockhart, 1999) while others indicate that the EKC does not hold for CO2 emissions (Yandle, Vijayaraghavan, and Bhattarai, 2002). Another widely cited study by Shafik (1994) finds an EKC relationship between per capita income and SO2 and particulate emissions but does not find such a relationship for $\mathrm{CO} 2$ emissions. Hence, it may be worthwhile to examine the validity of Kuznets curve for $\mathrm{CO} 2$ emissions.

In the absence of any a priori information on the functional form of the relationship between emissions and the GDP, we estimate two commonly used functional forms: linear and log linear. The advantage of the log linear formulation of this relationship is that slope coefficients represent elasticity measures. Therefore, each estimated coefficient indicates the percentage change in emissions for one percentage growth in GDP. Estimated functions are as follows: 


$$
\begin{aligned}
& e m_{t}=\alpha+\beta G D P_{t}+u_{t} \\
& \operatorname{Lem}_{t}=\alpha+\beta L G D P_{t}+u_{t}
\end{aligned}
$$

Given that the data are pooled for several years and countries, there is a possibility that regression residuals may be correlated over time and across countries. Therefore, we use a methodology suggested by Newey and West (1987) which takes into account residual autocorrelation over time and heteroscedasticity across various country observations. IN the next section, we present and discuss the empirical findings.

\section{EMPIRICAL RESULTS}

Estimation results of equations (1) and (2) are presented Table 1 and 2. According to these findings, there is a positive relationship between GDP and emissions. Empirical results presented in Table 1 show that the linear model of equation (1) may not capture the relationship between emissions and the GDP. All statistical indicators, i.e., the F and $t$ statistics are insignificant. The measure of goodness of fit, $\mathrm{R}^{2}$ is expectedly low for this pooled time series and cross sectional data set. Furthermore, in an attempt to isolate the relationship between emissions and the GDP, we have left out other variables which may play a role in this model. However, regression results are not robust when GDP measures are changed from nominal to real. In addition, statistical significance of the GDP in the $\log \operatorname{linear}$ functional form suggests that the relationship maybe not linear. Table 2 shows that for one percent change in GDP, emissions rise by $0.09-0.12$ percent. This measure is statistically significant in the regression of emissions on the nominal GDP. Table 2 also shows that the $\mathrm{R}^{2}$ of the log linear model has improved and the F statistic is significant.

TABLE 1

Estimation results of Equation (1)

Autocorrelation-Heteroscedasticity Consistent Estimates

\begin{tabular}{lcccc}
\hline Dependent & $\boldsymbol{\alpha}$ & $\boldsymbol{\beta}$ & $\mathbf{R}^{2}$ & $\mathbf{F}$ \\
\hline Emissions & $360027.0^{* * * *}$ & 0.0003 & 0.004 & 1.607 \\
& $(3.06)$ & $(1.30)$ & & 0.003 \\
Emissions & $362053.0^{* * * *}$ & 0.0002 & 0.80 \\
& $(3.08)$ & $(1.25)$ & &
\end{tabular}

Notes: ${ }^{k * * * * * *}$ significant at 1 and 5 percent levels, $t$ statistics are reported in parentheses

TABLE 2

Estimation results of Equation (2)

Autocorrelation-Heteroscedasticity Consistent Estimates

\begin{tabular}{lcccc}
\hline Dependent & $\boldsymbol{\alpha}$ & $\boldsymbol{\beta}$ & $\mathbf{R}^{2}$ & $\mathbf{F}$ \\
\hline Emissions & $10.1^{* * * *}$ & $0.12^{* * *}$ & 0.12 & 36.71 \\
& $(12.59)$ & $(2.10)$ & & \\
Emissions & $10.42^{* * *}$ & 0.09 & 0.06 & 18.46 \\
& $(12.40)$ & $(1.58)$ & & \\
\hline
\end{tabular}

Notes: ${ }^{* * * * * * *}$ significant at 1 and 5 percent levels, $\mathrm{t}$ statistics are reported in parentheses

The debate over pollution has long held that there may be a nonlinear pattern in emissions. Thus, it is appropriate to test for the Kuznets Curve by disaggregating the data into possibly three different classifications: predeveloping, developing, and developed. Disaggregated regression equations may shed further light on the relationship between emissions and economic growth for these categories. This investigation is important because it may isolate the sources of emission problems more accurately. 
Tables 3 and 4 report estimation results necessary for this part of the analysis. Both tables indicate that the $\beta$ coefficients are highly significant and positive. Therefore, at all stages of economic development, nations appear to be moving toward higher equilibrium levels of emissions and GDP at any given time. In the following we discuss the percentage change in emissions due to percentage changes in GDP growth.

TABLE 3

Estimation results of Equation (1) Autocorrelation-Heteroscedasticity Consistent Estimates

\begin{tabular}{lcccc}
\hline Category & $\boldsymbol{\alpha}$ & $\boldsymbol{\beta}$ & $\mathbf{R}^{2}$ & $\mathbf{F}$ \\
\hline Low & $-2.88^{* * * *}$ & $0.001^{* * *}$ & 0.67 & $491.19^{* * *}$ \\
\multirow{2}{*}{ Medium } & $(-10.16)$ & $(14.26)$ & & \\
& $-27.03^{* * *}$ & $0.003^{* * *}$ & 0.68 & $1038.94^{* * * *}$ \\
High & $(-2.70)$ & $(7.63)$ & & \\
& $-33.24^{* * *}$ & $0.007^{* * *}$ & 0.92 & $4105.89^{* * *}$ \\
Notes: ${ }^{* * * *}$ significant at 1 percent level & $(26.16)$ & &
\end{tabular}

TABLE 4

Estimation results of Equation (2) Autocorrelation-Heteroscedasticity Consistent Estimates

\begin{tabular}{lcccc}
\hline Category & $\boldsymbol{\alpha}$ & $\boldsymbol{\beta}$ & $\mathbf{R}^{2}$ & $\mathbf{F}$ \\
\hline Low & $-8.10^{* * * *}$ & $21.04^{* * * *}$ & 0.76 & $763.63^{* * *}$ \\
\multirow{2}{*}{ Medium } & $(-25.44)$ & $(26.14)$ & & \\
& $-8.02^{* * *}$ & $1.14^{* * *}$ & 0.91 & $4744.01^{* * *}$ \\
High & $(-52.34)$ & $(75.32)$ & & \\
& $-5.26^{* * *}$ & $0.83^{* * *}$ & 0.83 & $1648.40^{* * *}$ \\
\hline
\end{tabular}

Notes: ${ }^{* * * *}$ significant at 1 percent level, $\mathrm{t}$ statistics are reported in parentheses

Table 4 shows the estimation results of equation (II). The $\beta$ coefficients represent the percentage change in emissions with respect to percentage change in GDP. According to these estimates, the highest percentage contributors to emissions in the process of expanding consumption are countries in the low development category of nations (Human Development Index [HDI] values less than .05; for example, Pakistan and Nigeria). This is followed by the medium development category of nations (HDI values between 0.5 and 0.8 ; for example, China and Venezuela). The lowest percentage contributors are the countries in the high development category (HDI values greater than 0.8; for example, Norway and United States). (See Hill and Adrangi 1999 for a recent listing of HDI values across all nations of the world.) However, GDP coefficients reported in Table 4 indicate that while early stages of GDP growth contribute significantly to $\mathrm{CO} 2$, at higher levels of economic growth the contribution of growth to emissions declines as evidenced by the low value of the estimated coefficient.

Two possible explanations emerge: First, at the lowest levels of economic development, nations may have fewer resources and therefore less ability to influence environmental quality as the GDP and consumption expand. Second, at low levels of GDP nations often grow at faster rates (e.g., double-digit growth rates), resulting in relatively higher emissions levels as a by-product of expanding consumption. A logical inference is that at the highest levels of economic development, nations have more resources to allocate to pollution control and environmental management. An example is the European Union enforcing strict controls on emissions. Second, the rate of GDP growth usually 
does not exceed 2-5\%, producing lower relative added emissions as a by-product of expanding consumption. These findings are consistent with the environmental Kuznets curve which, states that the relationship between GPD and emissions an inverted $U$ curve. Our findings demonstrate that the marginal emissions rise initially with rises in GDP and subsequently fall as GDP rises beyond a certain level.

\section{SUMMARY CONCLUSIONS}

In this paper, we presented a theoretical model of the relationship between emissions, the GDP values and the costs involved in reducing emissions. The model is set up as a constrained optimization model and first-order conditions are derived for functional linkages of the arguments. The second order conditions are arranged in a bordered Hessian to check for sufficiency.

The empirical section of the paper tests the relationship between $\mathrm{CO} 2$ emissions and GDP across nation states as well as within the UN categories of developed, developing, and under-developed countries. Results show that the GDP growth contributes to the $\mathrm{CO} 2$ emissions regardless of the level of economic growth in a nation.

Furthermore, we find that in nations at the lowest stage of economic development growth is accompanied by high rate of emissions. As nations enjoy higher levels of economic growth, the rate of $\mathrm{CO} 2$ emissions initially stabilize and are the lowest for nations at the highest levels of GDP. These findings are consistent with the EKC.

We offer two possible explanations for these findings: First, nations at the lowest levels of economic development, may allocate more resources to economic development and fewer resources to improve environmental quality as the GDP and consumption expand. Second, at low levels of GDP growth rates are higher than for nations at higher levels of DGP, resulting in relatively higher emissions levels as a by-product of expanding GDP and consumption levels.

For instance, while the U.S. economic growth in the last decade has often been below five percent, India and China have experienced GDP growth rates in excess of seven percent. However, in the last year, the government of China has taken measures to attend to some of the serious environmental negative externalities caused by its pace of economic growth.

One may conclude that the income effect of the rising GDP in developing nations rise is more demand for luxury goods, including a healthier environment. In response, governments may be able to allocate more resources out of the growing GDP and tax revenues to pollution abatment and environmental quality.

Second, at higher GDP levels, the rate of GDP growth usually does not exceed 2-5 percent, producing lower marginal rates of emissions. These findings are consistent with the environmental Kuznets curve which, states that the relationship between GPD and emissions an inverted $U$ curve. Our findings demonstrate that the marginal emissions rise initially with rises in GDP and subsequently fall as GDP rises beyond a certain level. 
Figure

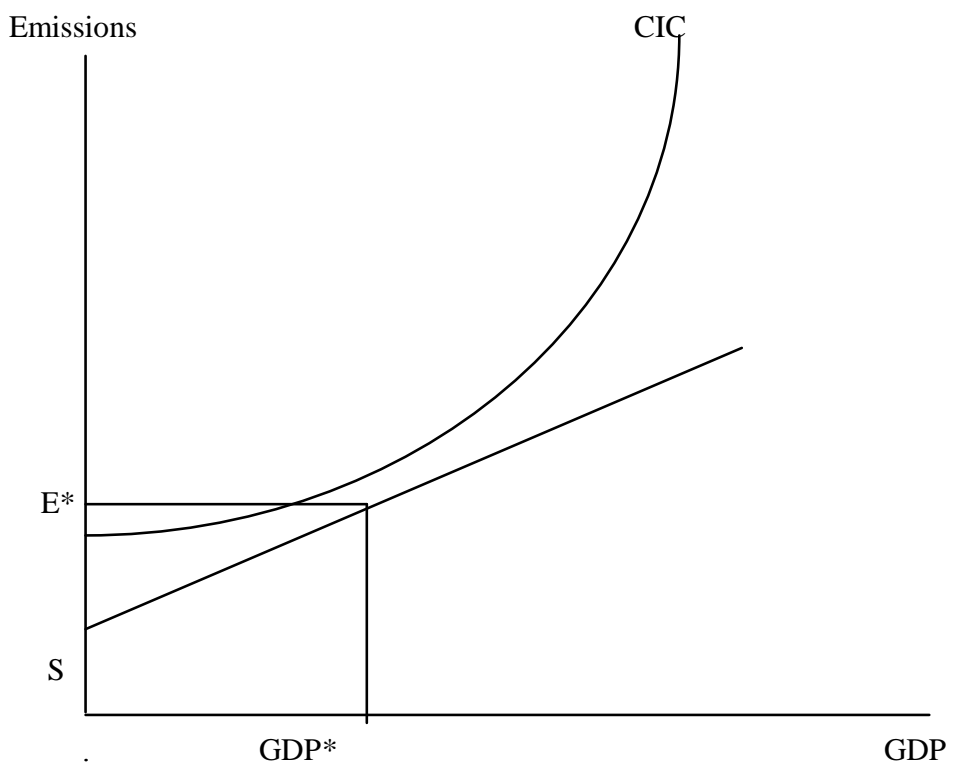

APPENDIX

Annex A Of The Kyoto Protocol

\begin{tabular}{|c|c|}
\hline $\begin{array}{l}\text { Greenhouse Gases: } \\
\text { Carbon dioxide (CO2) } \\
\text { Methane (CH4) } \\
\text { Nitrous oxide (N2O) } \\
\text { Hydrofluorocarbons (HFCs) } \\
\text { Perfluorocarbons (PFCs) } \\
\text { Sulphur hexafluoride (SF6) }\end{array}$ & $\begin{array}{l}\text { Sectors/Source Categories: } \\
\text { Energy } \\
\text { Fuel combustion } \\
\text { Energy industries } \\
\text { Manufacturing industries and construction } \\
\text { Transport } \\
\text { Other sectors } \\
\text { Other }\end{array}$ \\
\hline $\begin{array}{l}\text { Solvent and Other Product Use: } \\
\text { Agriculture } \\
\text { Enteric fermentation } \\
\text { Manure management } \\
\text { Rice cultivation } \\
\text { Agricultural soils } \\
\text { Prescribed burning of savannas } \\
\text { Field burning of agricultural residues } \\
\text { Other }\end{array}$ & $\begin{array}{l}\text { Industrial Processes: } \\
\text { Mineral products } \\
\text { Chemical industry } \\
\text { Metal production } \\
\text { Other production } \\
\text { Production of halocarbons and sulphur hexafluoride } \\
\text { Consumption of halocarbons and sulphur hexafluoride } \\
\text { Other }\end{array}$ \\
\hline $\begin{array}{l}\text { Fugitive Emissions from Fuels: } \\
\text { Solid fuels } \\
\text { Oil and natural gas } \\
\text { Other }\end{array}$ & $\begin{array}{l}\text { Waste: } \\
\text { Solid waste disposal on land } \\
\text { Wastewater handling } \\
\text { Waste incineration } \\
\text { Other }\end{array}$ \\
\hline
\end{tabular}


Annex B Of The Kyoto Protocol

\begin{tabular}{|l|c|l|c|}
\hline $\begin{array}{l}\text { Party Quantified Emission } \\
\text { Limitation or Reduction }\end{array}$ & $\begin{array}{c}\text { Percentage of } \\
\text { Base Year or } \\
\text { Period }\end{array}$ & $\begin{array}{l}\text { Party Quantified Emission } \\
\text { Limitation or Reduction } \\
\text { Commitment }\end{array}$ & $\begin{array}{c}\text { Percentage of } \\
\text { Base Year or } \\
\text { Period }\end{array}$ \\
\hline Australia & 108 & Liechtenstein & 92 \\
Austria & 92 & Lithuania* & 92 \\
Belgium & 92 & Luxembourg & 92 \\
Bulgaria* & 92 & Monaco Netherlands & 92 \\
Canada & 94 & New Zealand & 92 \\
Croatia* & 95 & Norway & 100 \\
Czech Republic* & 92 & Poland* & 101 \\
Denmark & 92 & Portugal & 94 \\
Estonia* & 92 & Romania* & 92 \\
European Community & 92 & Russian Federation* & 100 \\
Finland & 92 & Slovakia* & 92 \\
France & 92 & Slovenia* & 92 \\
Germany & 92 & Spain & 92 \\
Greece & 92 & Sweden & 92 \\
Hungary* & 94 & Switzerland & 100 \\
Iceland & 110 & Ukraine* & 92 \\
Ireland & 92 & United Kingdom of Great & 93 \\
Italy & 92 & Britain and Northern Ireland & \\
Japan & 94 & United States of America & \\
Latvia* & 92 & & \\
\hline
\end{tabular}

* Countries that are undergoing the process of transition to a market economy

Derivation of second-order conditions, the bordered Hessian and the sign of the determinant

From equations (7), (9) and (11), we can derive the following second-order conditions:

$\mathrm{L}_{\mathrm{GDP}, \mathrm{GDP}}=\alpha(\alpha-1) \mathrm{GDP}^{\alpha-1} \mathrm{EM}^{-\beta}$

$\mathrm{L}_{\mathrm{GDP}, \mathrm{EM}}=-\alpha \beta \mathrm{GDP}^{\alpha-1} \mathrm{EM}^{-\beta-1}$

$\mathrm{L}_{\mathrm{GDP}, \lambda}=-\psi$

$\mathrm{L}_{\mathrm{EM}, \mathrm{GDP}}=-\alpha \beta \mathrm{GDP}^{\alpha-1} \mathrm{EM}^{-\beta-1}$

$\mathrm{L}_{\mathrm{EM}, \mathrm{EM}}=-\beta(-\beta-1) \mathrm{GDP}^{\alpha} \mathrm{EM}^{-\beta-2}$

$\mathrm{L}_{\mathrm{EM}, \lambda}=\mu$

$\mathrm{L}_{\lambda, \mathrm{GDP}}=-\psi$

$\mathrm{L}_{\mu, \mathrm{e}}=\mu$

$\mathrm{L}_{\mu, \mu}=0$ 
Hence, the determinant of the Hessian is:

$$
\left|\begin{array}{ccc}
\alpha(\alpha-1) G D P^{\alpha-1} E M^{-\beta} & -\alpha \beta G D P^{\alpha-1} E M^{-\beta-1} & -\psi \\
-\alpha \beta G D P^{\alpha-1} E M^{-\beta-1} & -\beta(-\beta-1) G D P^{\alpha} E M^{-\beta-2} & \mu \\
-\psi & \mu & 0
\end{array}\right|
$$

Expanding on the minors in the first row and calculating the determinants of the $2 \mathrm{X} 2$ matrices, we get:

$-\alpha(\alpha-1) \mu^{2} \mathrm{GDP}^{\alpha-1} \mathrm{EM}^{-\beta}+\mu \psi \alpha \beta \mathrm{GDP}^{\alpha-1} \mathrm{EM}^{-\beta-1}+\alpha \beta \mu \psi \mathrm{GDP}^{\alpha-1} \mathrm{EM}^{-\beta-1}+\beta \psi^{2}(-\beta-1) \mathrm{GDP}^{\alpha} \mathrm{EM}^{-\beta-2}$

The second and the third terms in the above expression are positive, and for the determinant of the matrix to be positive definite, we need the following condition to hold:

$$
\begin{aligned}
& \left|\alpha(\alpha-1) \mu^{2} \mathrm{GDP}^{\alpha-1} \mathrm{EM}^{-\beta}\right|>\left|\beta \psi^{2}(-\beta-1) \mathrm{GDP}^{\alpha} \mathrm{EM}^{-\beta-2}\right| \\
& \mu^{2} \alpha(\alpha-1) / \mathrm{GDP}>\psi^{2} \beta(\beta-1) / \mathrm{EM}
\end{aligned}
$$

If the inequality in equation (11) is held, it ensures the positive definiteness of the bordered hessian matrix. Given that society is concerned about pollution, it is natural that the price of pollution will be relatively high. If the marginal cost of pollution is high, then the inequality in equation (11) will hold.

\section{REFERENCES}

1. Gupta, S. (2000), “Operationalizing the CDM", RIIA Workshop Report available at http://www.riia.org/ Research/eep/publications.org/.

2. "Kyoto Protocol Status of Ratification" (2004), available at http://unfccc.int/resource/kpstats.pdf.

3. "Kyoto Ratification Timetable in Doubt" (2002), available at http://www.eceee.org/latest_news/2002/ News20020523b.lasso.

4. Dhanda, K., B. Adrangi, and R. Hill, “A Model of Consumption And Environmental Degradation: Making the Case For Sustainabile Consumer Behavior," Journal of Human Development, Forthcoming.

5. Newey, Whitney K., and K. West (1987), “A Simple Positive-Definite Heteroscedasticity and Autocorrelation Consistent Covariance Matrix,” Econometrica, 55, 703-708, 1987.

6. "Putin tells Ministries to Salvage Kyoto" (2003), available at http://news.daylightonline.com/Kyoto.html.

7. Selden, Thomas, Forrest Anne, and James Lockhart, "Analyzing the Reductions in U.S. Air Pollution Emissions: 1970 to 1990”, Land Economics, February, 1999, 75(1), 1-21.

8. Shafik, Nemat, "Economic Development and Environmental Quality: An Econometric Analysis", Oxford Economic Papers, 46, 757-777.

9. Vrojilk, C. and M. Grubbs (2000), "Quantifying Kyoto: How will COP-6 decisions affect the market?", RIIA Workshop Report, available at http://www.riia.org/Research/eep/publications.org/.

10. Text of the Kyoto Protocol (1997), available at http://www.unfccc.int/resource/docs/convkp/kpeng.html.

11. "UN Climate Change Convention" (1997), Press Release accessed 29 December, available at http://www.unep.ch/iuc/submenu/press/climate/pr12-97.htm.

12. "U.S., Canada and Mexico may set up emissions trading" (2003), available at http://www.globalclimate.org/ newsroom/ccinthenews.htm.

13. Yandle, Bruce, Vijayaraghavan, Maya and Madhusudan Bhattarai, "The Environmental Kuznets Curve: A Primer", PERC Research Study, May 2002. 